\title{
Glass transition, crystallization kinetics and pressure effect on crystallization of ZrNbCuNiBe bulk metallic glass
}

Xing, P.F.; Zhuang, Yanxin; Wang, W.H.; Gerward, Leif; Jiang, Jianzhong

Published in:

Journal of Applied Physics

Link to article, DOI:

$10.1063 / 1.1461892$

Publication date:

2002

Document Version

Publisher's PDF, also known as Version of record

Link back to DTU Orbit

Citation (APA):

Xing, P. F., Zhuang, Y., Wang, W. H., Gerward, L., \& Jiang, J. (2002). Glass transition, crystallization kinetics and pressure effect on crystallization of ZrNbCuNiBe bulk metallic glass. Journal of Applied Physics, 91(8), 4956-4960. https://doi.org/10.1063/1.1461892

\section{General rights}

Copyright and moral rights for the publications made accessible in the public portal are retained by the authors and/or other copyright owners and it is a condition of accessing publications that users recognise and abide by the legal requirements associated with these rights.

- Users may download and print one copy of any publication from the public portal for the purpose of private study or research.

- You may not further distribute the material or use it for any profit-making activity or commercial gain

- You may freely distribute the URL identifying the publication in the public portal 


\title{
Glass transition, crystallization kinetics and pressure effect on crystallization of ZrNbCuNiBe bulk metallic glass
}

\author{
P. F. Xing and Y. X. Zhuang a) \\ Institute of Physics \& Center for Condensed Matter Physics, Chinese Academy of Science, P.O. Box 603, \\ Beijing 100080, People's Republic of China, School of Materials and Metallurgy, Northeastern \\ University, Shenyang, 110006, People's Republic of China, and Department of Physics, Building 307, \\ Technical University of Denmark, DK-2800 Lyngby, Denmark \\ W. H. Wang \\ Institute of Physics \& Center for Condensed Matter Physics, Chinese Academy of Science, P.O. Box 603, \\ Beijing 100080, People's Republic of China \\ L. Gerward and J. Z. Jiang \\ Department of Physics, Building 307, Technical University of Denmark, DK-2800, Lyngby, Denmark
}

(Received 24 July 2001; accepted for publication 28 January 2002)

\begin{abstract}
The glass transition behavior and crystallization kinetics of $\mathrm{Zr}_{48} \mathrm{Nb}_{8} \mathrm{Cu}_{14} \mathrm{Ni}_{12} \mathrm{Be}_{18}$ bulk metallic glass have been investigated by differential scanning calorimetry and x-ray powder diffraction (XRD). The activation energies of both glass transition and crystallization events have been obtained using the Kissinger method. Results indicate that this glass crystallizes by a three-stage reaction: (1) phase separation and primary crystallization of glass, (2) formation of intermetallic compounds, and (3) decomposition of intermetallic compounds and crystallization of residual amorphous phase. The pressure effect on crystallization is studied by in situ high-pressure and high-temperature XRD using synchrotron radiation. Two crystallization temperatures, observed by in-situ XRD, behave differently with varying pressure. The onset crystallization temperature increases with pressure with a slope of $9.5 \mathrm{~K} / \mathrm{GPa}$ in the range of 0 to $4.4 \mathrm{GPa}$, while the another crystallization temperature keeps almost unchanged in the applied pressure range. The results are attributed to the competing processes between the thermodynamic potential barrier and the diffusion activation energy under pressure. (c) 2002 American Institute of Physics. [DOI: 10.1063/1.1461892]
\end{abstract}

\section{INTRODUCTION}

The crystallization investigation of metallic glasses is of importance in understanding mechanisms of phase transformation far from equilibrium, in evaluating the glass forming ability of the melts and thermal stability of metallic glasses, and in producing controlled ultrarefined microstructure with expected shapes. ${ }^{1-3}$ It is found that the crystallization process is sensitive to alloy composition, ${ }^{4}$ applied pressure,,${ }^{5-10}$ annealing temperature, ${ }^{11,12}$ and heating rate ${ }^{13}$ so on. Schroers et al. ${ }^{13}$ has proved that a rate of about $200 \mathrm{~K} / \mathrm{s}$ upon heating can avoid any crystallization events in the $\mathrm{Zr}_{41} \mathrm{Ti}_{14} \mathrm{Cu}_{12.5} \mathrm{Ni}_{10} \mathrm{Be}_{22.5}$ bulk metallic glass. Previous work $^{5-10,14,15}$ has proved that applied pressure has a noticeable effect on crystallization, and is a powerful tool for modifying and controlling microstructure of metallic glasses. The very fine-grained nanostructural materials can be obtained by controlling crystallization of metallic glasses. The investigation of crystallization kinetics and glass transition behavior may provide a way for insight into the mechanism of the nucleation and growth process, and nature of glass transition and crystallization reaction in metallic glasses, because the activation energy is closely related to the local atomic structure. On the other hand, the glass transition is one of the most important and intensive investigated topics

\footnotetext{
${ }^{a)}$ Electronic mail: yxzhuang@fysik.dtu.dk
}

in the area of metallic glasses; however, a comprehensive understanding of the glass transition is still lacking. The discovery of bulk metallic glasses (BMG) with excellent glass forming ability, wide supercooled liquid region, and high thermal stability against crystallization offers a chance for investigating the glass transition behavior, phase transformation, nucleation, and growth in the supercooled liquid region in a long time scale, and exploring the potential application of metallic glasses. ${ }^{16,17}$

In this work, the glass transition and crystallization behavior of $\mathrm{Zr}_{48} \mathrm{Nb}_{8} \mathrm{Cu}_{14} \mathrm{Ni}_{12} \mathrm{Be}_{18}$ bulk metallic glass with a wide supercooled liquid region and high thermal stability ${ }^{18}$ have been studied by differential scanning calorimeter (DSC) and x-ray diffraction (XRD). The apparent activation energies of the glass transition and crystallization are determined using the Kissinger method. The pressure effect on the crystallization process in this BMG was also monitored by in-situ high-pressure and high-temperature x-ray powder diffraction using synchrotron radiation in pressure range of 0 to 4.4 GPa.

\section{EXPERIMENTS}

The ingots, with a composition $\mathrm{Zr}_{48} \mathrm{Nb}_{8} \mathrm{Cu}_{14} \mathrm{Ni}_{12} \mathrm{Be}_{18}$, were prepared by melting a mixture of elements in a titanium-gettered arc furnace, remelting in a vacuum-sealed quartz tube, and then quenching in water to get an amor- 
phous rod with a diameter of $8 \mathrm{~mm}$ and a length of $50 \mathrm{~mm}$. The amorphous nature as well as the homogeneity of the rod was ascertained with XRD and transmission electron microscope (TEM). Slices with a thickness of $0.5 \mathrm{~mm}$ were cut from the amorphous rod for annealing and DSC measurements. The samples were annealed in a furnace with a vacuum of $2.0 \times 10^{-2} \mathrm{~Pa}$. The XRD measurements were processed by a Philips PW 1820 diffractometer with $\mathrm{Cu} \mathrm{K} \mathrm{K}_{\alpha}$ radiation in order to identify the crystalline phases formed after different crystallization reactions. DSC measurements were carried out under a purified argon atmosphere in a Perkin-Elmer DSC7 at the heating rate, $\varnothing$ ranging from 5 to $200 \mathrm{~K} / \mathrm{min}$ at the ambient pressure. The calorimeter was calibrated for temperature and energy at various heating rates with high purity indium and zinc. First, an empty Al pan was tested to establish a baseline, then the same Al pan including the sample was used at the identical thermal condition. The values of the glass transition temperature $\left(T_{g}\right)$, the onset temperature for first crystallization events $\left(T_{x 1}\right)$, and the crystallization peak temperature $\left(T_{p i}\right)$ were determined from the DSC traces with an accuracy of $\pm 1 \mathrm{~K}$. In-situ highpressure and high-temperature energy-dispersive $\mathrm{X}$-ray diffraction (EDXRD) measurements were performed using synchrotron radiation at HASYLAB in Hamburg, Germany, by the MAX 80 station a multianvil pressure apparatus with 8 mm cube pressure cells. ${ }^{19}$ The cubic sample assembly is compressed by six truncation anvils of tungsten carbide in a 250 ton hydraulic press. Electric current is sent through a graphite heater via two appropriate anvils. The temperature is measured by thermocouple with a stability of $\pm 1 \mathrm{~K}$. The pressure, $P$, of the sample is calculated from the lattice constant of $\mathrm{NaCl}$ using the Decker equation of state. ${ }^{20}$ Each run consists of isothermal room-temperature compression followed by isobaric heating up to $873 \mathrm{~K}$ in steps of $10 \mathrm{~K}$ in order to observe crystallization temperatures at different pressures. The average heating rate in the temperature range from 298 to $873 \mathrm{~K}$ was roughly estimated to be $1 \mathrm{~K} / \mathrm{min}$. Pure $\mathrm{Zr}, \mathrm{Fe}$, and the BMG powders were used to examine the possible oxidation of samples during the heat treatments using the high-pressure sample assembly. It was found that only pure metallic phases in the three systems were detected after heat treatment at temperatures up to $873 \mathrm{~K}$ under pressure.

\section{RESULTS AND DISCUSSION}

Figure 1 gives typical continuous DSC traces obtained for $\mathrm{Zr}_{48} \mathrm{Nb}_{8} \mathrm{Cu}_{14} \mathrm{Ni}_{12} \mathrm{Be}_{18} \mathrm{BMG}$ at various heating rates of 5, $10,20,40,80,120,160$, and $200 \mathrm{~K} / \mathrm{min}$. All the DSC traces exhibit the endothermic characteristics of a glass transition followed by exothermic reactions at higher temperatures, indicating that the BMG has a wide supercooled liquid region and crystallizes by multistep reactions. The first two peaks are very close while third one is a tiny peak located at a higher temperature, which is very similar to those of the $\mathrm{Zr}_{41} \mathrm{Ti}_{14} \mathrm{Cu}_{12.5} \mathrm{Ni}_{10} \mathrm{Be}_{22.5}$ BMG. ${ }^{21,22}$ The values of $T_{g}, T_{x 1}$, $T_{p 1}, T_{p 2}$, and $T_{p 3}, \Delta T=T_{x 1}-T_{g}$, determined by DSC at $10 \mathrm{~K} / \mathrm{min}$ for the $\mathrm{Zr}_{48} \mathrm{Nb}_{8} \mathrm{Cu}_{14} \mathrm{Ni}_{12} \mathrm{Be}_{18}$ glass are 661,715 , $725,739,834$, and $54 \mathrm{~K}$, respectively, while 625, 691, 710,

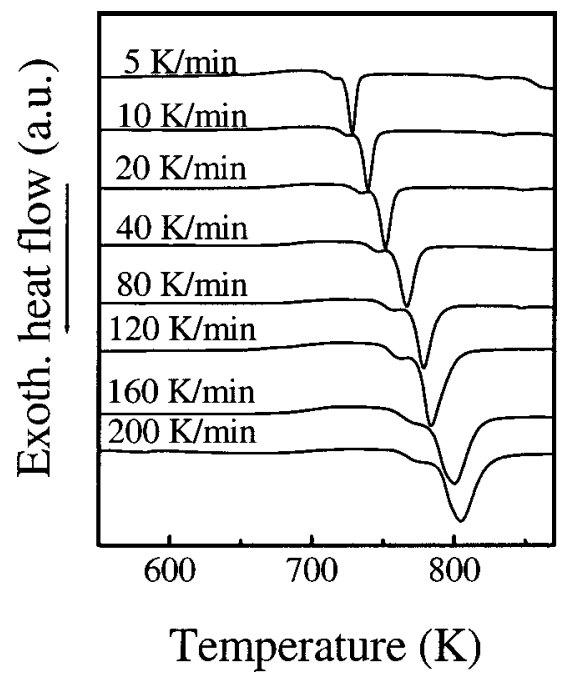

FIG. 1. DSC traces for the as-prepared $\mathrm{Zr}_{48} \mathrm{Nb}_{8} \mathrm{Cu}_{14} \mathrm{Ni}_{12} \mathrm{Be}_{18}$ bulk metallic glass at different heating rates. The first crystallization peak is sensitive to the heating rate, and its area and intensity decrease with increasing heating rate.

730, 769, and $66 \mathrm{~K}$ for the $\mathrm{Zr}_{41} \mathrm{Ti}_{14} \mathrm{Cu}_{12.5} \mathrm{Ni}_{10} \mathrm{Be}_{22.5}$ glass. The larger supercooled liquid region $(\Delta T)$ and much higher value of $T_{g}$ and $T_{x 1}$ of the $\mathrm{Zr}_{48} \mathrm{Nb}_{8} \mathrm{Cu}_{14} \mathrm{Ni}_{12} \mathrm{Be}_{18}$ alloy compared to that of the $\mathrm{Zr}_{41} \mathrm{Ti}_{14} \mathrm{Cu}_{12.5} \mathrm{Ni}_{10} \mathrm{Be}_{22.5}$ glass indicate that the alloy has excellent glass forming ability and can be applied at higher temperatures.

From Fig. 1, it is clearly seen that $T_{g}, T_{x 1}$, and $T_{p i}$ of the BMG are shifted to higher temperature with increasing heating rate. Not only crystallization but also glass transition display dependence on heating rate during continuous heating. Another interesting feature is that the first crystallization peak is sensitive to the heating rate, which is very similar to that of $\mathrm{Zr}_{41} \mathrm{Ti}_{14} \mathrm{Cu}_{12.5} \mathrm{Ni}_{10} \mathrm{Be}_{22.5}$ glass. ${ }^{6}$ Its area and intensity decrease with increasing heating rate. At a high heating rate (160 K/min), it almost disappears as shown in Fig. 1, indicating the crystallization event has a low critical heating rate for suppressing the nucleation and growth. Figure 2 exhibits that the endothermic broad peak of the BMG shifts gradually to higher temperatures, the width of supercooled liquid region increases with increasing heating rate, and the glass transition process is delayed to higher temperatures. This phenomenon indicates that the glass transition as well as the crystallization behaves in a marked kinetic nature. The dependence of the $T_{g}, T_{x}$, and $T_{p i}$ on heating rate can be described by Lasocka's relationship: ${ }^{23}$

$$
T=A+B \ln \phi,
$$

where $A$ and $B$ are constants for a given composition and some particular temperature $T$. The data of $T_{g}$ versus $\ln \phi$ for the alloy and fitting line with Eq. (1) are shown in inset of Fig. 2. The good fitting result verifies that $T_{g}$ can be well described by Lasocka's relationship. The values of $A$ and $B$ are different for the glass transition and crystallization reactions as displayed in Fig. 3(a), e.g., the value of $B$ is 7.62 for $T_{g}, 13.86$ for $T_{x 1}, 17.91$ for $T_{p 1}$, and 20.38 for $T_{p 2}$. It can be deduced that the crystallization shows stronger dependence on heating rate than glass transition. The apparent ac- 


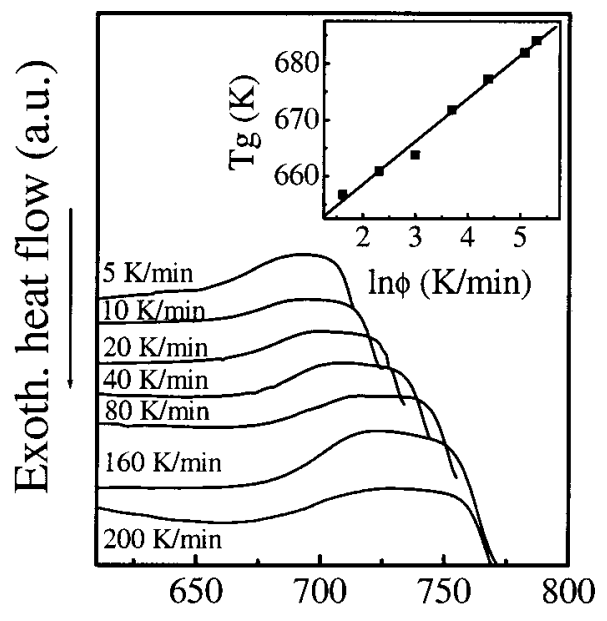

Temperature (K)

FIG. 2. DSC traces for the as-prepared $\mathrm{Zr}_{48} \mathrm{Nb}_{8} \mathrm{Cu}_{14} \mathrm{Ni}_{12} \mathrm{Be}_{18}$ bulk metallic glass showing the dependence of $T_{g}$ and $\Delta T$ on the heating rate. The inset shows the plots of $T_{g}$ vs $\ln \phi$ for the bulk metallic glass.

tivation energy for the glass transition and crystallization reactions $E_{g}$ and $E_{p i}$ can be determined by Kissinger's equation: ${ }^{24}$

$$
\ln \frac{T^{2}}{\phi}=\frac{E}{R T}+\ln \frac{E}{R K_{0}},
$$
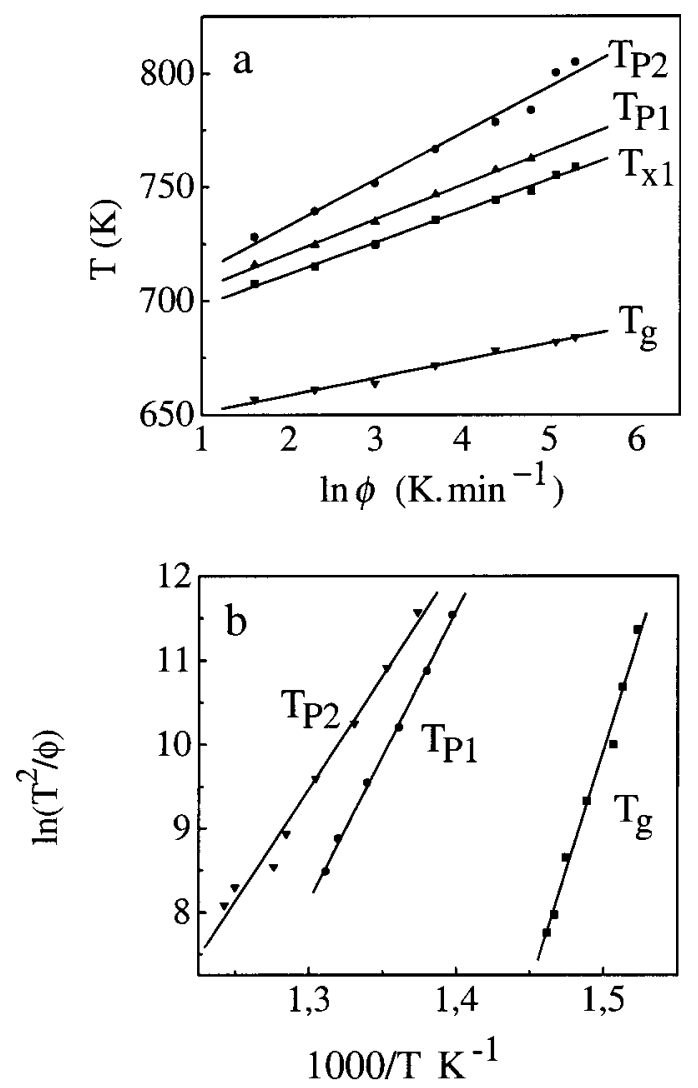

FIG. 3. Lasocka's Plots (a) and Kissinger Plots (b) of glass transition and crystallization events obtained from the DSC measurements for the asprepared $\mathrm{Zr}_{48} \mathrm{Nb}_{8} \mathrm{Cu}_{14} \mathrm{Ni}_{12} \mathrm{Be}_{18}$ bulk metallic glass.

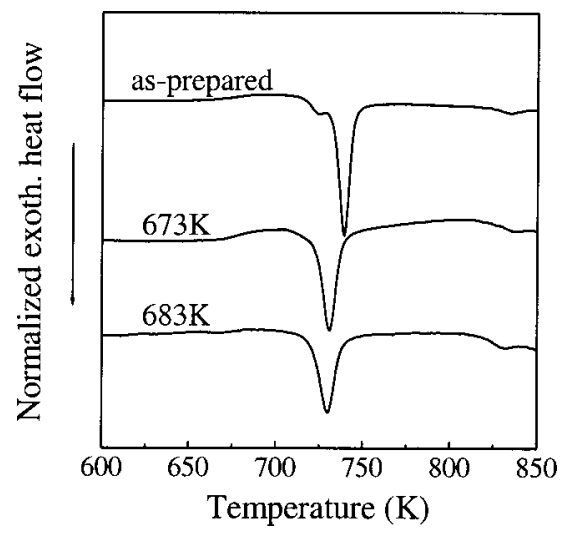

FIG. 4. DSC traces for the as-prepared $\mathrm{Zr}_{48} \mathrm{Nb}_{8} \mathrm{Cu}_{14} \mathrm{Ni}_{12} \mathrm{Be}_{18}$ bulk metallic glass and specimens annealed at $673 \mathrm{~K}$ or $683 \mathrm{~K}$ for $1 \mathrm{~h}$. The heating rate is $10 \mathrm{~K} / \mathrm{min}$.

where $R$ is the gas constant, $K_{0}$ is the frequency factor in Arrehenius's law, that is, $K_{T}=K_{0} \exp (-E / R T)$. The Kissinger plots of the glass transition and crystallization for the alloy are shown in Fig. 3(b). The $E_{g}, E_{p 1}$, and $E_{p 2}$ are $468.98,287.29$, and $222.90 \mathrm{~kJ} / \mathrm{mol}$, respectively. $E_{g}$ is much smaller, $E_{p 1}$ is greater, and $E_{p 2}$ is smaller than those of $\mathrm{Zr}_{41} \mathrm{Ti}_{14} \mathrm{Cu}_{12.5} \mathrm{Ni}_{10} \mathrm{Be}_{22.5}$ BMG. ${ }^{12,2}$

To further study the phase formation in process of crystallization, the disks of the bulk metallic glass were annealed under vacuum at different annealing temperatures $T_{a}$ and then measured by TEM, DSC, or standard XRD. Figure 4 shows the continuous DSC traces at the heating rate of 10 $\mathrm{K} / \mathrm{min}$ for as-prepared alloy and specimen annealed in the supercooled liquid region for $1 \mathrm{~h}$. The annealing in the supercooled liquid induces the disappearance of the first crystallization peak and the shift of the second crystallization peak to a lower temperature. The normalized exothermal heat flow for the second crystallization reaction decreases with the annealing temperature increasing, indicating that fraction of phase transformation increases. No crystalline peaks are observed from XRD patterns of the alloys annealed at 673 and $683 \mathrm{~K}$ (not shown). The first crystallization peak in the $\mathrm{Zr}_{48} \mathrm{Nb}_{8} \mathrm{Cu}_{14} \mathrm{Ni}_{12} \mathrm{Be}_{18}$ alloy could be attributed to the phase separation and primary crystallization, which is similar to that of the $\mathrm{Zr}_{41} \mathrm{Ti}_{14} \mathrm{Cu}_{12.5} \mathrm{Ni}_{10} \mathrm{Be}_{22.5}$ alloy. This can be verified by TEM observation for the samples annealed in the supercooled liquid region. Figure 5 illustrates bright-field TEM images and corresponding selected area electron diffraction patterns of one sample annealed at $673 \mathrm{~K}$. The bright-field micrograph reveals nanoparticles embedded in the amorphous for the annealing sample, while corresponding selected area electron diffraction suggests that the inner ring of diffraction pattern of the annealing samples splits to two scattering rings. This phenomenon has also been observed in the $\mathrm{Zr}_{41} \mathrm{Ti}_{14} \mathrm{Cu}_{12.5} \mathrm{Ni}_{10} \mathrm{Be}_{22.5}$ alloy, ${ }^{25,26}$ which perhaps indicates that the phase separation is involved in the crystallization process of the $\mathrm{Zr}_{48} \mathrm{Nb}_{8} \mathrm{Cu}_{14} \mathrm{Ni}_{12} \mathrm{Be}_{18} \mathrm{BMG}$ and induces the precipitation of nano-amorphous particles with different composition in the BMG. The preannealing of the $\mathrm{ZrNbCuNiBe} \mathrm{BMG}$ in the supercooled liquid region may 


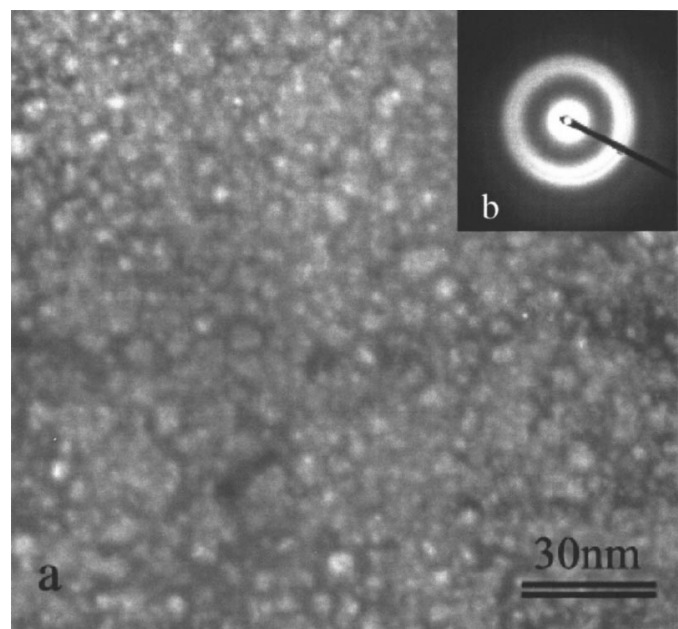

FIG. 5. Bright-field TEM image (a) and corresponding selected area electron diffraction patterns (b) for the $\mathrm{Zr}_{48} \mathrm{Nb}_{8} \mathrm{Cu}_{14} \mathrm{Ni}_{12} \mathrm{Be}_{18}$ bulk metallic glass annealed at $673 \mathrm{~K}$

induce phase separation, nucleation, and growth of nuclei upon the annealing conditions.

Figure 6 shows XRD patterns of as-prepared glass together with diffraction patterns obtained after annealing at selected temperatures of 728,753 , and $873 \mathrm{~K}$. The pattern of the sample annealed at $728 \mathrm{~K}$ for $2 \mathrm{~h}$ shows Bragg peaks of $\mathrm{Zr}_{2} \mathrm{Ni}$-like, $\mathrm{Be}_{2}(\mathrm{ZrNi})$-like, and $\mathrm{Zr}_{2} \mathrm{Cu}$-like phases, superimposed on the broad diffuse scattering peak from the amorphous phase. When the temperature increases to $753 \mathrm{~K}$, the crystallization phases remain while the intensities of the crystalline components increase, indicating the fraction of crystallization phases increase. The XRD results suggest that the second crystallization reaction is related to the formation of $\mathrm{Zr}_{2} \mathrm{Ni}$-like, $\mathrm{Be}_{2}(\mathrm{ZrNi})$-like, and $\mathrm{Zr}_{2} \mathrm{Cu}$-like intermetallic components. For the sample annealed at $873 \mathrm{~K}\left(>T_{p 3}\right)$ for 3 $\mathrm{h}$, the XRD pattern is much different from others. Many

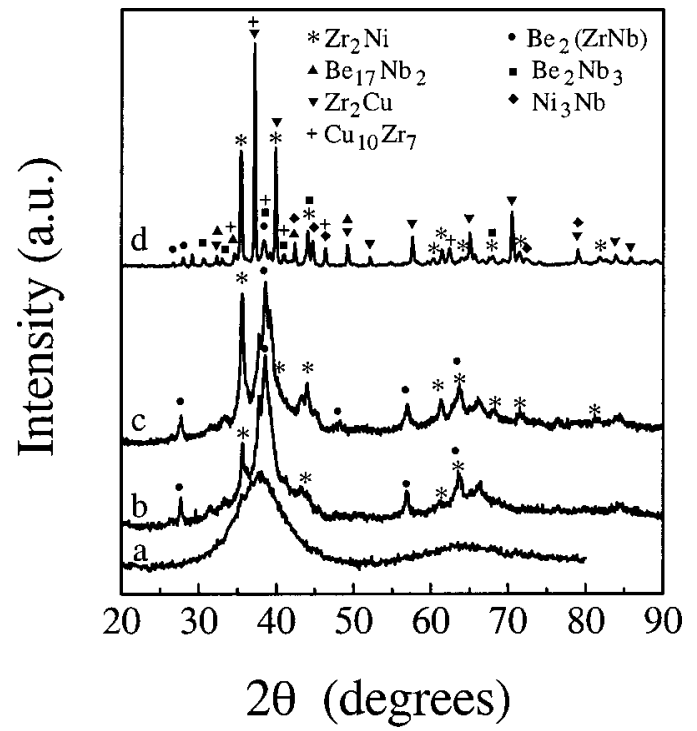

FIG. 6. X-ray diffraction patterns recorded at room temperature using a Philips PW 1820 diffractometer with $\mathrm{Cu}-\mathrm{K}_{\alpha}$ radiation for the as-prepared $\mathrm{Zr}_{48} \mathrm{Nb}_{8} \mathrm{Cu}_{14} \mathrm{Ni}_{12} \mathrm{Be}_{18}$ bulk metallic glass (a) and the samples annealed at $728 \mathrm{~K}(\mathrm{~b}), 753 \mathrm{~K}(\mathrm{c})$, and $873 \mathrm{~K}(\mathrm{~d})$.

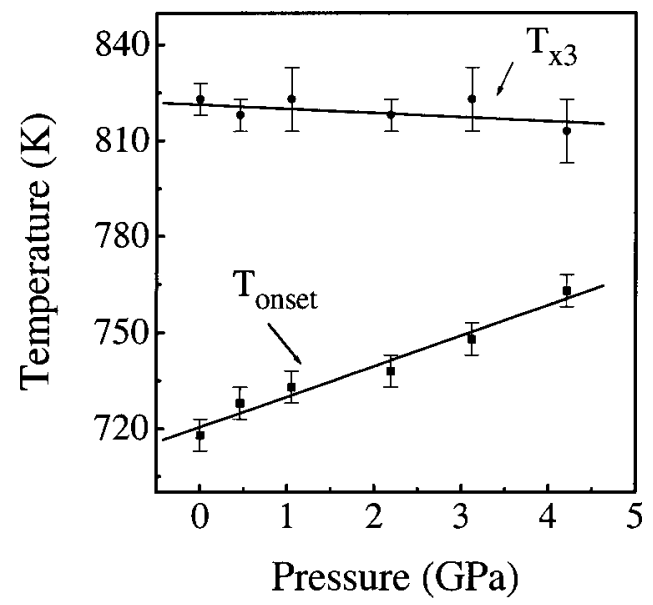

FIG. 7. Crystallization temperatures of the $\mathrm{Zr}_{48} \mathrm{Nb}_{8} \mathrm{Cu}_{14} \mathrm{Ni}_{12} \mathrm{Be}_{18}$ bulk metallic glass as a function of pressure. The data are linearly fitted as solid lines.

intermetallic compounds, including $\mathrm{Cu}_{10} \mathrm{Zr}_{7}, \mathrm{NiZr}_{2}, \mathrm{Zr}_{2} \mathrm{Cu}$, $\mathrm{Ni}_{3} \mathrm{Nb}, \mathrm{Be}_{2} \mathrm{Nb}_{3}, \mathrm{Be}_{17} \mathrm{Nb}_{2}$, and $\mathrm{Be}_{2} \mathrm{Zr}$ can be identified as marked in Fig. 6(d) This result infers that the third peak observed by DSC is most likely due to decomposition of the $\mathrm{Be}_{2}(\mathrm{ZrNb})$-like phase and crystallization of the residual amorphous phase.

High pressure can modify the nucleation and growth behavior in metallic glasses, and then affect their crystallization process. The in-situ high-pressure and high-temperature EDXRD patterns of the BMG were recorded every $10 \mathrm{~K}$ for various applied pressure to observe the onset temperature of crystallization with an uncertainty of $10 \mathrm{~K}$ in the pressure range of 0 to $4.4 \mathrm{GPa}$. It is found that the crystalline phases formed and the sequence of phase formation during crystallization process of the BMG are identical in the applied pressure range. Two crystallization reactions can be detected by EDXRD. The first one is attributed to the formation of $\mathrm{Zr}_{2} \mathrm{Ni}$-like, $\mathrm{Be}_{2}(\mathrm{ZrNi})$-like, and $\mathrm{Zr}_{2} \mathrm{Cu}$-like phases, while the second one corresponds to decomposition of the $\mathrm{Be}_{2}(\mathrm{ZrNb})$-like phase and crystallization of the residual amorphous phase. Figure 7 gives the two crystallization temperatures, which was estimated from EDXRD patterns recorded, with a increasing temperature step size of about 10 $\mathrm{K}$. It is clearly seen that the applied pressure strongly affects the crystallization temperatures of the $\mathrm{Zr}_{48} \mathrm{Nb}_{8} \mathrm{Cu}_{14} \mathrm{Ni}_{12} \mathrm{Be}_{18}$ BMG. The behaviors of the two crystallization temperatures versus pressure are different. The onset crystallization temperature, $T_{\text {onset }}$, observed by EDXRD, increased with the applied pressure with a slope of $9.5 \mathrm{~K} / \mathrm{GPa}$. The value is similar to those reported for other metallic glasses in the literatures, e.g., $19 \mathrm{~K} / \mathrm{GPa}$ for the $\mathrm{Zr}_{41.2} \mathrm{Ti}_{14.8} \mathrm{Cu}_{12.5} \mathrm{Ni}_{10} \mathrm{Be}_{22.5}$ in the range of 0 to $4 \mathrm{GPa},{ }^{27} 11 \mathrm{~K} / \mathrm{GPa}$ for $\mathrm{Pa}_{40} \mathrm{Cu}_{30} \mathrm{Ni}_{10} \mathrm{P}_{20}$ in the pressure range of 0 to $4 \mathrm{GPa}^{10}$ and $9.4 \mathrm{~K} / \mathrm{GPa}$ for $\mathrm{Zr}_{65} \mathrm{Al}_{7.5} \mathrm{Ni}_{10} \mathrm{Cu}_{7.5} \mathrm{Ag}_{10}$ in the range of 0 to $4.14 \mathrm{GPa}^{28}$ The applied pressure has no insignificant influence on the second crystallization temperature $T_{x 3}$ determined by EDXRD as marked in Fig. 7.

Crystallization of metallic glass is normally regarded as a process proceeding by nucleation and subsequent growth of crystals. The onset crystallization temperature of a metal- 
lic glass, i.e., at the initial stage of nucleation, may be governed by the thermodynamic potential barrier of nucleation and diffusion activation energy. According to crystallization kinetics theory, the nucleation rate, $I$, can be written as $I$ $=I_{0} \exp \left(\Delta G^{*}+Q_{n}\right) / k_{B} T$, where $I_{0}$ is a constant, $\Delta G^{*}$ is the free energy required to form a nucleus of the critical size, i.e., the thermodynamic potential barrier of nucleation, $Q_{n}$, is the activation energy for the transport of an atom across the interface of an embryo, $k_{B}$ is Boltzmann's constant. The sum, $\Delta G^{*}+Q_{n}$, is called the nucleation work. The onset crystallization of the $\mathrm{Zr}_{48} \mathrm{Nb}_{8} \mathrm{Cu}_{14} \mathrm{Ni}_{12} \mathrm{Be}_{18}$ BMG, observed by in-situ high-temperature and high-pressure EDXRD, could correspond to formation of intermetallic compounds. The primary crystallization of the BMG requires long-range atomic diffusion due to a large composition between amorphous phase and its corresponding crystallization products. This implies that the crystallization is controlled by diffusion. The pressure dependence of $Q_{n}$ might be responsible for the behavior of $T_{\text {onset }}$ versus pressure. In general, pressure could reduce atomic mobility. This means that the $Q_{n}$ might increase with pressure. Hence, the nucleation work increases with pressure. Consequently, nucleation rate decreases with pressure and an enhancement of crystallization temperature is expected, as observed for the onset crystallization temperature of the $\mathrm{Zr}_{48} \mathrm{Nb}_{8} \mathrm{Cu}_{14} \mathrm{Ni}_{12} \mathrm{Be}_{18}$ BMG in the range of 0 to $4.4 \mathrm{GPa}$. For the $T_{x 3}$ versus $P$, it could be tentatively explained as follows. As results showed above, this crystallization event could be related to the decomposition of $\mathrm{Be}_{2}(\mathrm{ZrNb})$-like intermetallic compounds and formation of new intermetallic compounds. The interfacial energies for intermetallic compounds are large. It is expected that the $\Delta G^{*}$, rather than $Q_{n}$ could become the dominant factor for the nucleation rate., $\Delta G^{*}$ is proportional to interfacial energy of nucleus and $1 /(P \Delta V+\Delta G)^{2}$, where $\Delta V$ and $\Delta G$ are the change of molar volume and free energy due to the phase transformation. If the term, $P \Delta V$, is much smaller than $\Delta G$, $\Delta G^{*}$ is then insensitive to pressure. This implies that $T_{x 3}$ is almost constant with respect to pressure although the atomic rearrangement may be involved in the event.

\section{CONCLUSION}

The glass transition behavior and crystallization kinetics of the $\mathrm{Zr}_{48} \mathrm{Nb}_{8} \mathrm{Cu}_{14} \mathrm{Ni}_{12} \mathrm{Be}_{18}$ bulk metallic glass have been investigated by DSC and XRD. The activation energies of glass transition and crystallization events for the glass have been obtained using Kissinger analysis. The glass transition as well as crystallization can be regarded as a kinetically modified thermodynamics phase transformation process. This BMG with a wide supercooled liquid region crystallizes by multistep reactions. The first crystallization reaction could correspond to the phase separation and primary crystallization. $\mathrm{Zr}_{2} \mathrm{Ni}$-like, $\mathrm{Be}_{2}(\mathrm{ZrNi})$-like, and $\mathrm{Zr}_{2} \mathrm{Cu}$-like, intermetallic compounds are formed after the second crystallization event. The third crystallization reaction could be related to the decomposition of $\mathrm{Be}_{2}(\mathrm{ZrNi})$-like intermetallic compounds and crystallization of residual amorphous phases. The crystallization studies under high-pressure and hightemperature $\mathrm{x}$-ray powder diffraction shows that the onset crystallization temperature increases upon pressure with a slope of $9.5 \mathrm{~K} / \mathrm{GPa}$ in the range of 0 to $4.4 \mathrm{GPa}$, the results can be explained by the suppression of atomic mobility under pressure. The other crystallization temperature is almost unchanged with respect to the pressure.

\section{ACKNOWLEDGMENTS}

The authors are grateful to the financial support of the National Natural Science Foundation of China (Grant Nos. 59925101 and 50031010) and Danish Technical Research Council and the Danish Natural Sciences Research Council. We thank ESRF in Grenoble and HASLYLAB in Hamburg for use of synchrotron radiation facilities.

${ }^{1}$ A. L. Greer, Mater. Sci. Eng., A 179/180, 41 (1996).

${ }^{2}$ H. S. Chen, J. Non-Cryst. Solids 27, 257 (1978).

${ }^{3}$ M. C. Weinberg, Thermochim. Acta 280/281, 63 (1996).

${ }^{4}$ W. H. Wang and H. Y. Bai, J. Appl. Phys. 64, 5961 (1998).

${ }^{5}$ K. Samwer, R. Busch, and W. L. Johnson, Phys. Rev. Lett. 82, 580 (1999).

${ }^{6}$ W. H. Wang, Y. X. Zhuang, M. X. Pan, and Y. S. Yao, J. Appl. Phys. 88, 3914 (2000).

${ }^{7}$ J. Z. Jiang, J. S. Olsen, L. Gerward, S. Abdali, J. Eckert, N. Schlorke-de Boer, L. Schutlz, J. Truckenbrodt, and P. X. Shi, J. Appl. Phys. 87, 2664 (2000)

${ }^{8}$ Y. X. Zhuang, J. Z. Jiang, T. J. Zhou, H. Rasmussen, L. Gerward, M. Mezouar, W. Crichton, and A. Inoue, Appl. Phys. Lett. 77, 4133 (2000).

${ }^{9}$ M. X. Pan, J. G. Wang, Y. S. Yao, D. Q. Zhao, and W. H. Wang, Appl. Phys. Lett. 78, 601 (2001).

${ }^{10}$ J. Z. Jiang, Y. X. Zhuang, H. Rasmussen, N. Nishiyama, A. Inoue, and C. Lathe, Europhys. Lett. 54, 182 (2001).

${ }^{11}$ W. Liu, W. L. Johnson, S. Schneider, U. Geyer, and P. Thiyagarajan, Phys. Rev. B 59, 11755 (1999).

${ }^{12}$ Y. X. Zhuang and W. H. Wang, J. Appl. Phys. 87, 8209 (2000).

${ }^{13}$ J. Schroers, A. Masuhr, W. L. Johnson, and R. Busch, Phys. Rev. B 60, 11855 (1999).

${ }^{14}$ W. K. Wang, Y. J. Wang, S. Q. He, and H. Iwasaki, Z. Phys. B: Condens. Matter 69, 481 (1988).

${ }^{15}$ W. H. Wang, D. W. He, D. Q. Zhao, Y. S. Yan, and M. He, Appl. Phys. Lett. 75, 2770 (1999).

${ }^{16}$ A. Inoue, Acta Mater. 48, 279 (2000).

${ }^{17}$ W. L. Johnson, MRS Bull. 24, 42 (1999).

${ }^{18}$ Y. Zhang, D. Q. Zhao, R. J. Wang, M. X. Pan, and W. H. Wang, Mater. Trans., JIM 41, 1423 (2000).

${ }^{19}$ J. S. Olsen, L. Gerward, and J. J. Jiang, J. Phys. Chem. Solids 60, 229 (1999).

${ }^{20}$ D. L. Decker, J. Appl. Phys. 42, 3239 (1971).

${ }^{21}$ R. Busch, Y. J. Kim, and W. L. Johnson, J. Appl. Phys. 77, 4039 (1995).

${ }^{22}$ Y. X. Zhuang, W. H. Wang, Y. Zhang, M. X. Pan, and D. Q. Zhao, Appl. Phys. Lett. 75, 2392 (1999).

${ }^{23}$ T. M. Lasocka, Mater. Sci. Eng. 23, 173 (1976).

${ }^{24}$ H. E. Kissinger, J. Res. Natl. Bur. Stand., Sect. A 57, 217 (1956).

${ }^{25}$ W. H. Wang, Q. Wei, and S. Friedrich, Phys. Rev. B 57, 8211 (1998).

${ }^{26}$ S. Schneider, U. Geyer, P. Thiyagarajan, R. Busch, R. Schultz, K. Samwer, and W. L. Johnson, Mater. Sci. Forum 225-227, 59 (1996).

${ }^{27}$ J. Z. Jiang, T. J. Zhou, H. K. Rasmussen, U. Kuhn, J. Eckert, and C. Lathe, Appl. Phys. Lett. 77, 3553 (2000).

${ }^{28}$ J. Z. Jiang, Y. X. Zhuang, H. Rasmussen, J. Saida, and A. Inoue, Phys. Rev. B 64, 094208 (2001). 